\title{
Effects of Amlodipine and Hydrochlorothiazide Combination Therapy on Lipid Profiles in Hypertensive Nigerians
}

\author{
G.B.S. Iyalomhe ${ }^{1, *}$, E.K.I. Omogbai ${ }^{2}$, O.O.B. Iyalomhe ${ }^{3}$ \\ ${ }^{1}$ Department of Pharmacology and Therapeutics, College of Medicine, Ambrose Alli University, Ekpoma, Nigeria \\ ${ }^{2}$ Department of Pharmacology and Toxicology, Faculty of Pharmacy, University of Benin, Benin City, Nigeria \\ ${ }^{3}$ Department of Physiology, School of Medicine, Johns Hopkins University, Baltimore, USA \\ *Corresponding author: goddyiyalo@yahoo.com
}

Received December 25, 2012; Revised March 29, 2013; Accepted April 29, 2013

\begin{abstract}
There is paucity of information regarding the effects of combination therapy with amlodipine and hydrochlorothiazide on lipid profiles in hypertensive Nigerians. Therefore, to evaluate whether this combination therapy would ameliorate or aggravate the known metabolic adversity of hydrochlorothiazide on lipid parameters, 90 male and female Nigerians aged 31-86 years with newly diagnosed uncomplicated essential hypertension (blood pressure $>160 / 90 \leq 180 / 120 \mathrm{mmHg}$ ) were enrolled into a randomised 48-week study. Treatment was initiated in the patients, who were 30 each in amlodipine, hydrochlorothiazide and amlodipine-hydrochlorothiazide groups, with amlodipine $5 \mathrm{mg}$, hydrochlorothiazide $25 \mathrm{mg}$ and amlodipine $5 \mathrm{mg}+$ hydrochlorothiazide $25 \mathrm{mg}$, respectively. Body mass index, blood pressure and lipid profiles were evaluated at baseline as well as at the end of weeks 1, 3, 6, 12, 24, 36 and 48. The 3 regimens significantly $(\mathrm{p}<0.05)$ reduced blood pressure. At the end of week 48 , mean male/female \% significant decrease or increase in lipid parameters in amlodipine, hydrochlorothiazide and amlodipine-hydrochlorothiazide groups were, respectively: $-4.3 /-1.5,2.8 / 3.7$ and $2.6 / 2.5, \mathrm{p}<0.0001$ for total cholesterol; - $-7.2 /-2.6,5.3 / 5.6$ and 6.6/6.2, $\mathrm{p}<0.0001$ for triglyceride; $16.5 / 19.6,-12.0 /-8.6$ and $-7.8 /-8.4, \mathrm{p}<0.0001$ for high density lipoprotein cholesterol; -4.6/-3.0, 5.6/11.7 and 4.5/8.0, $\mathrm{p}<0.0001$ for low density lipoprotein cholesterol. This study demonstrates that beyond reducing blood pressure, amlodipine and hydrochlorothiazide combination therapy has varied effects on lipid panel and it also suggests that, with regard to cardiovascular risk profile, it may be preferable to initiate treatment with a regimen of amlodipine to which hydrochlorothiazide is subsequently added, instead of a regimen of hydrochlorothiazide to which amlodipine is later added or a regimen of ab initio amlodipinehydrochlorothiazide combination therapy.
\end{abstract}

Keywords: Amlodipine, hydrochlorothiazide, antihypertensive combination therapy, lipid profiles, nigerians

\section{Introduction}

Worldwide, hypertension remains one of the most important risk factors for cardiovascular (CV) morbidity and mortality and imposes a major public health challenge on both developed and developing countries [1,2]. The prevalence of hypertension in Nigerian adults $\geq 18$ years of age is above 25\% [3]. According to Imam and Olorunfemi [4] and Ike [5], uncontrolled hypertension among Nigerian patients is responsible for excessive premature mortaliy and life-threatening events, such as myocardial infarction (MI), stroke, coronary heart disease (CHD), heart failure (HF) and chronic kidney disease (CKD).

Abundant evidence has demonstrated that dyslipidaemia including high concentrations of low density lipoprotein cholesterol (LDL) and triglyceride (TG) are strong risk factors for the development of cardiovascular diseases (CVDs) [6,7]. Thus, recent guidelines have emphasized comprehensive risk factor control as well as effective blood pressure (BP) treatment so as to decrease the incidence of $\mathrm{CV}$ events in these patients $[8,9,10,11]$.

Pharmacological treatment of essential hypertension has largely evolved from simple drug therapy to combinations of drugs exhibiting different mechanisms of action. The main objective of such practices is to effectively control BP, as this decreases CV morbidity and mortality associated with high BP and reduce adverse effects $[12,13]$. The critical import of early aggressive BP control is supported by recent guidelines that encourage the use of initial combination therapy when monotherapy is unlikely to be sufficient $[13,14,15,16]$.

Accumulating evidence indicates that specific classes of antihypertensive agents may exhibit a wide range of effects on lipid metabolism beyond their BP-lowering effect $[17,18]$ : while some exert beneficial or neutral effects on lipid profiles, others adversely affect it $[17,18]$. Accordingly, previous studies have demonstrated that the long-acting dihydropyridine calcium channelblockers (CCBs), particularly amlodipine (AML), exert beneficial effects on lipid profiles through their anti-atherogenic, 
anti-oxidant, anti-inflammatory and anti-proliferative effects as well as potentiation of nitric oxide activity $[17,18,19,20,21]$. On the other hand, thiazides, such as hydrochlorothiazide (HCZ), have been reported to negatively affect lipid status [18,22,23,24,25,26].

In the light of the above and given the attenuated response of black hypertensive patients to angiotensin converting enzyme inhibitors (ACEIs), angiotensin $\mathrm{AT}_{1}$ receptor blockers (ARBs) and beta-blockers (BBs) [13,27,28,29], the use of AML and HCZ as first-line or combination treatment of essential hypertension has become a popular option in Nigeria [29]. This is because apart from their effectiveness in specifically addressing the low renin, salt-sensitive and volume-dependent hypertension that is characteristic of this population, these drugs are also comparatively cheap, available and tolerable [31,32].

Although the association between antihypertensive agents such as AML and HCZ and lipid parameters is well established, very little is known about the effects of the combination treatment on lipid profiles in hypertensive Nigerians. In other words, it is conjectural whether AML will ameliorate the hostile effects of thiazides on lipid panel. Therefore, the current study was designed to determine the effects of dual combination treatment of AML and HCZ on lipid profiles in hypertensive Nigerians.

\section{Materials and Methods}

\subsection{Study Population}

Ninety male (M) and female (F) Nigerians with newly diagnosed essential hypertension (stages 1 and 2) aged 3186 years who were attending Central Hospital and Osigbemhe Hospital both in Auchi in Edo State of Nigeria between March 2008 and March 2009 were enrolled into a randomised, prospective, open-label 48-week study. The sample size was estimated based on the number of Nigerians that are believed to be hypertensive [3]. To detect a difference of 2 units in mean change in the measured variables, between both treatment arms with a power equal to $90 \%$ using a one sample t-test at a onesided significance level of 0.05 , this requires 30 patients per group.

Eligible participants had qualifying hypertension of BP $>160 / 90$ and $\leq 180 / 120 \mathrm{mmHg}$ measured on at least 2 occasions in lying/supine, sitting and standing positions using standardized methods [33]. Excluded were patients with identifiable cause of the hypertension, clinical evidence of cerebrovascular, cardiac, renal, hepatic, gastrointestinal or endocrinologic disease, hypersensitivity to AML and HCZ or related drugs, history of smoking, alcohol intake, substance abuse or mental illness. Also excluded were patients needing any concomitant medication eg digitalis, non-steroidal anti-inflammatory drugs, psychotropic drugs, monoamine oxidase inhibitors or oral contraceptives, that may interact with the trial drugs and pregnant or lactating $\mathrm{F}$.

The research protocol was reviewed and approved by the Ethics Committees of Irrua Specialist Teaching Hospital Irrua, Nigeria (Ambrose Alli University College of Medicine Teaching Hospital) and Central Hospital Auchi, Nigeria. After suitable explanation of the study protocol, all literate patients gave informed written consent and the illiterates thumb-printed the consent form before the beginning of the study.

\subsection{Study Design}

Subjects were examined by a standardized pre-tested questionnaire seeking information on demographic data, the history of hypertension, current drugs if any, educational and social status, dietary habits, smoking and alcohol intake, etc. The 90 patients were randomized to three groups (AML, HCZ and AML-HCZ groups) each comprising 30 patients who were divided into subgroups of $15 \mathrm{M}+15 \mathrm{~F}$ using computer program-generated random numbers.

\subsection{Measurements of Heights (m), Weights (wt) (kg) and BP (mmHg)}

A stadiometer scale (Seca model, UK) was used for measuring height, with no shoes on and a beam balance (Hackman, UK) was used to measure wt while on light clothing. BMI was computed as wt divided by height squared. systolic BP (SBP) and diastolic BP (DBP) were measured with a standard mercury sphygmomanometer (Riester Diplomat Presameter, Germany) using standardized methods [33] at the sitting, standing and supine positions; always between 8am and 10am. All constricting clothing on the upper arm were removed before any measurement and subjects were discouraged from talking or moving during measurements. The first phase of the Korotkov sound was regarded as the SBP while the fifth phase was regarded as the DBP. During measurement, readings were taken two consecutive times with an interval of at least one minute and the average recorded. During the study, subjects were not told the results of BP measurement.

\subsection{Antihypertensive Intervention}

AML group was treated initially with AML $5 \mathrm{mg}$ and the dose was doubled after 6 weeks if BP was not controlled. Then after 12 weeks (end of monotherapy), HCZ 25mg was added if goal BP was not still achieved. $\mathrm{HCZ}$ group was treated initially with HCZ $25 \mathrm{mg}$ for 6 weeks (end of monotherapy), after which AML 5mg was added if BP was uncontrolled. The dose of AML was doubled after 12 weeks if BP was still not normalized. AML-HCZ group was initially treated with AML $5 \mathrm{mg}+$ HCZ 25mg. If BP was not controlled after 6 weeks, the dose of AML was doubled. The outpatient treatment lasted 48 weeks. The patients were monitored closely and outcome measures evaluated at baseline before treatment as well as at the end of weeks 1, 3, 6, 12, 24, 36 and 48 during treatment. Unequivocal patient identification was possible via a patient identification list consisting of the patient number, first name and surname.

The study medications AML and HCZ are licensed for long-term treatment of hypertension so that dangerous side effects due to the medicaments were not to be expected. AML 5mg and 10mg tablets $\left(\right.$ Amlovar $^{\mathrm{R}}$ ), were donated by Neimeth International Pharmaceuticals Ikeja, Nigeria: NAFDAC Reg No A4-0333; Manufacturing Date 07-2007 and Expiry Date 07-2010. HCZ 25mg tablets $\left(\right.$ Esidrex $^{\mathrm{R}}$ ) were donated by Novartis Pharma SAS 
Nigerian Representative, NAFDAC Reg No OL-3705, Manufacturing Date 08-2007 and Expiry Date 08-2010.

\subsection{Course of Study and Methods for Recording Efficacy and Safety}

All patients were advised to maintain their usual diet (weight-maintaining no-salt-added diet) and regular physical activity but to avoid undue stress throughout the duration of the study. They were instructed to take their drugs every morning. Each patient was observed for about 2 hours after taking medication drug for the first time. Adherence in respect of intake of medication was encouraged by interviewing patients through phone calls, sporadic visits and pill counts outside the view of patients. To accurately assess the efficacy of the drugs, patients were followed up repeatedly at weeks $1,3,6,12,24,36$ and 48 .

Response to therapy as regards the BP measurement was defined as a decrease in the mean trough sitting SBP and DBP of $10 \mathrm{mmHg}$ or a drop to $<90 \mathrm{mmHg}$ with reduction of $>5 \mathrm{mmHg}$. BP was regarded as controlled if the DBP was $<90 \mathrm{mmHg}$ and SBP $<140 \mathrm{mmHg}$. The effects of treatment on the various variables (except height) were assessed by comparing the values at each visit with the pretreatment baseline values.

\subsection{Blood Sample Collection and Analysis}

At every visit, after an overnight fast of at least $8 \mathrm{~h}$, $10 \mathrm{ml}$ of blood was obtained from each patient by peripheral venipuncture into a plain sterile bottle. Serum was obtained by allowing the blood to clot and then centrifuged at 5000rpm for 5 minutes at room temperature. Serum lipid profiles were measured at baseline (week 0) and at the end of weeks 1, 3, 6, 12, 24, 36 and 48. Total cholesterol (TC) and triglyceride (TG) were determined enzymatically by the cholesterol oxidase method and the glycerol oxidase method, respectively [34] and high density lipoprotein cholesterol (HDL) by the phosphotungstate magnesium chloride method [34] and LDL was calculated using the formula of Friedewald et al. [35]. (Reagent kits manufactured by Randox Laboratories Ltd, Ardmore, Crumlin, UK).

\subsection{Data Analysis}

All data are presented as mean \pm SEM or mean \pm SD (for age, height and weight) using the general linear model procedure (PROC GLM) of the Statistical Analysis System [36]. Where significant differences were noticed, mean separation was carried out using Duncan Multiple Range Test. Correlation between two sets of variables was determined using Spearman's rank correlation. $\mathrm{p}<0.05$ was regarded as significant.

\section{Results}

As shown in Table 1, at baseline, there was no statistically significant difference in the $\mathrm{M} / \mathrm{F}$ patients in AML, HCZ and AML-HCZ groups, respectively, with regard to the means of ages $(60.80 \pm 14.03 / 63.60 \pm 8.02$, $63.80 \pm 12.02 / 65.47 \pm 10.15$ and $62.13 \pm 11.89 / 69.93 \pm 11.60$ years), BMIs $(26.50 \pm 0.80 / 27.50 \pm 0.31, \quad 26.50 \pm 0.32$ /
$24.50 \pm 0.42$ and $27.50 \pm 0.38 / 26.00 \pm 0.56 \mathrm{~kg} \mathrm{~m}^{-2}$ ) as well as the SBP $(162.50 \pm 2.82 / 165.67 \pm 3.00, \quad 170.33 \pm 2.09$ $/ 169.00 \pm 1.90$ and $165.00 \pm 4.57 / 167.50 \pm 4.44 \mathrm{mmHg}$ ) and DBP $\quad(103.00 \pm 1.75 / 105.33 \pm 2.04, \quad 104.67 \pm 1.50 /$ $104.67 \pm 1.98$ and $106.00 \pm 1.48 / 107.33 \pm 2.01 \mathrm{mmHg}$ ). Most of the patients had significant (stage 2) hypertension. The analysis excluded the data for a $\mathrm{M}$ patient in the AML group who travelled and so could not report for evaluation at week 48; a F from AML group who became pregnant and so was withdrawn from the study between weeks 36 and 48 as well as a $\mathrm{M}$ patient whose week 36 serum specimen was lost in AML-HCZ group.

Table 2 shows that the effects of treatment with AML, $\mathrm{HCZ}$ and AML-HCZ on M/F total serum cholesterol mean values $\quad(164.46 \pm 4.70 / 172.87 \pm 3.27, \quad 171.26 \pm 3.27 /$ $162.27 \pm 3.50$ and $165.93 \pm 4.43 / 169.00 \pm 3.53 \mathrm{mg} / \mathrm{dl})$, respectively, were significant $(\mathrm{p}<0.0001)$. In the $\mathrm{M}$ subgroups, there was a significant decrease in concentration in AML subgroup while there was a significant increase $(\mathrm{p}<0.0001)$ in $\mathrm{HCZ}$ and AML-HCZ subgroups. At week 48, the mean $\%$ decrease in $\mathrm{M}$ was $4.3 \%$ in AML subgroup and the \% increases were $2.8 \%$ and $2.6 \%$ in HCZ and AML-HCZ subgroups, respectively. In the $\mathrm{F}$ subgroups, although there was no significant change in TC concentration in AML subgroup, there was significant increases in $\mathrm{HCZ}$ and AML-HCZ subgroups $(p<0.0001)$. At week 48, the mean \% increases were $3.7 \%$ and $2.5 \%$ in $\mathrm{HCZ}$ and AML-HCZ subgroups, respectively. However, there was no significant difference in the gender effect $(\mathrm{p}<0.142)$.

As presented in Table 3, mean $M$ serum TG concentrations: $79.73 \pm 3.33,82.53 \pm 1.79$ and $87.93 \pm 3.30$ $\mathrm{mg} / \mathrm{dl}$ in AML, HCZ and AML-HCZ subgroups respectively, were significantly affected by treatment $(\mathrm{p}<0.0001)$. While concentration levels were decreased in AML subgroup, the reverse occurred in HCZ and AMLHCZ subgroups. At week 48, mean \% decrease in TG concentration in $\mathrm{M}$ was $7.2 \%$ in AML subgroup and the \% increases were $5.3 \%$ and $6.6 \%$ in $\mathrm{HCZ}$ and AML-HCZ subgroups, respectively. Baseline $\mathrm{F}$ serum $\mathrm{TG}$ concentrations: $83.66 \pm 3.18,76.48 \pm 1.25$ and $90.48 \pm 2.05$ $\mathrm{mg} / \mathrm{dl}$ in AML, HCZ and AML-HCZ subgroups respectively, were not significantly decreased in AML subgroup but significantly increased in HCZ and AMLHCZ subgroups $(\mathrm{p}<0.0001)$. At week 48 , mean $\%$ increases were $5.6 \%$ and $6.2 \%$ in HCZ and AML-HCZ subgroups, respectively. TG values were negatively correlated with DBP ( $\mathrm{r}=-0.0878),(\mathrm{p}=0.0191)$.

The baseline serum HDL mean values in M AML, HCZ and AML-HCZ subgroups were, respectively, 34.67 \pm 1.77 , $38.33 \pm 1.55$ and $40.00 \pm 1.36 \mathrm{mg} / \mathrm{dl}$ (Table 4). While treatment significantly increased HDL levels in AML subgroup ( $<<0.0001)$, the opposite was the case in HCZ and AML-HCZ subgroups. By week 48, the mean \% increase in HDL concentration was $16.5 \%$ in AML subgroup and the $\%$ decreases were $12.0 \%$ and $7.8 \%$ in HCZ and AML-HCZ subgroups, respectively. Similarly in the $F$ subgroups, baseline mean values: $39.13 \pm 0.66$, $34.80 \pm 1.92$ and $39.53 \pm 1.30 \mathrm{mg} / \mathrm{dl}$ in AML, HCZ and AML-HCZ subgroups respectively, were significantly increased in AML subgroup and decreased in the other subgroups $(p<0.0001)$. At the end of week 48 , the mean $\%$ increase in HDL concentration was $9.6 \%$ in AML subgroup and the $\%$ decreases were $8.6 \%$ and $8.4 \%$ in 
HCZ and AML-HCZ subgroups, respectively. Although, the differences in mean values and \% increases or decreases in the variable appear to the higher in $\mathrm{M}$ than $\mathrm{F}$, they were, however, not statistically significant $(\mathrm{p}<0.285)$.

Table 1. Demographic Characteristics and Baseline Blood Pressures of Subjects

\begin{tabular}{|c|c|c|c|c|c|}
\hline \multirow[b]{2}{*}{ Group } & \multirow[b]{2}{*}{ Characteristics } & \multicolumn{2}{|c|}{ Male } & \multicolumn{2}{|c|}{ Female } \\
\hline & & Range & Mean \pm SD/SEM $*$ & Range & Mean \pm SD/SEM \\
\hline \multirow{6}{*}{ AML } & Age (yrs) & $31-80$ & $60.80 \pm 14.03$ & $37-80$ & $63.60 \pm 8.02$ \\
\hline & Height (m) & $1.59-1.74$ & $1.66 \pm 0.04$ & $1.56-1.76$ & $1.66 \pm 0.07$ \\
\hline & Weight (kg) & $62-88$ & $76.77 \pm 8.94$ & $62-90.4$ & $79.80 \pm 8.85$ \\
\hline & BMI $\left(\mathrm{kg} \mathrm{m}^{-2}\right)$ & $24.84-29.75$ & $26.50 \pm 0.80$ & $25.48-30.13$ & $27.50 \pm 0.31$ \\
\hline & SBP (mmHg) & $150-175$ & $162.50 \pm 2.82$ & $150-180$ & $165.67 \pm 3.00^{*}$ \\
\hline & $\mathrm{DBP}(\mathrm{mmHg})$ & $100-115$ & $103.00 \pm 1.75$ & $90-115$ & $105.33 \pm 2.04^{*}$ \\
\hline \multirow{7}{*}{$\mathrm{HCZ}$} & Age (yrs) & $45-86$ & $63.80 \pm 12.02$ & $48-80$ & $65.47 \pm 10.15$ \\
\hline & Height (m) & $1.61-1.80$ & $1.69 \pm 0.05$ & $1.12-1.76$ & $1.67 \pm 0.04$ \\
\hline & Weight (kg) & $68-89$ & $75.37 \pm 6.27$ & $60-80$ & $73.44 \pm 6.30$ \\
\hline & BMI $\left(\mathrm{kg} \mathrm{m}^{-2}\right)$ & $26.25-27.47$ & $26.50 \pm 0.32$ & $23.17-26.67$ & $24.50 \pm 0.42$ \\
\hline & SBP (mmHg) & $160-180$ & $170.33 \pm 2.09^{*}$ & $160-180$ & $169.00 \pm 1.90^{*}$ \\
\hline & DBP (mmHg) & $95-115$ & $104.67 \pm 1.50^{*}$ & $90-115$ & $104.67 \pm 1.98^{*}$ \\
\hline & Age (yrs) & $42-78$ & $62.13 \pm 11.89$ & $48-87$ & $69.93 \pm 11.60$ \\
\hline \multirow{5}{*}{$\mathrm{AML}-\mathrm{HCZ}$} & Height (m) & $1.58-1.72$ & $1.64 \pm 0.04$ & $1.59-1.82$ & $1.67 \pm 0.06$ \\
\hline & Weight (kg) & $65-87.5$ & $74.33 \pm 7.07$ & $65-90.2$ & $77.21 \pm 8.67$ \\
\hline & BMI $\left(\mathrm{kg} \mathrm{m}^{-2}\right)$ & $26.10-29.66$ & $27.50 \pm 0.38$ & $25.79-27.33$ & $26.00 \pm 0.56$ \\
\hline & $\mathrm{SBP}(\mathrm{mmHg})$ & $150-180$ & $165.00 \pm 4.57^{*}$ & $155-180$ & $167.50 \pm 4.44^{*}$ \\
\hline & $\mathrm{DBP}(\mathrm{mmHg})$ & $100-115$ & $106.00 \pm 1.48^{*}$ & $90-120$ & $107.33 \pm 2.01^{*}$ \\
\hline
\end{tabular}

Characteristics and BPs in the groups are not significantly different; AML, Amlodipine; HCZ, Hydrochlorothiazide, AML-HCZ, Amlodipinehydrochlorothiazide combination; BMI, Body mass index; SBP, Systolic blood pressure; DBP, Diastolic blood pressure; *, Standard error of mean; (N = $30[15 \mathrm{M}+15 \mathrm{~F}]$ per group)

Table 2. Effects of AML and HCZ Combination Therapy on Total Cholesterol (mg/dl) in Hypertensive Subjects for 48 weeks

\begin{tabular}{|c|c|c|c|c|c|c|c|}
\hline & \multicolumn{3}{|c|}{ Treatment Subgroups (Male) } & \multicolumn{3}{|c|}{ Treatment Subgroups (Female) } & \\
\hline Week & AML & $\mathrm{HCZ}$ & AML-HCZ & AML & $\mathrm{HCZ}$ & AML-HCZ & Gender Effect \\
\hline 0 & $164.46 \pm 4.70$ & $171.26 \pm 3.27$ & $165.93 \pm 4.43$ & $172.87 \pm 3.27$ & $162.27 \pm 3.50$ & $169.00 \pm 3.53$ & \multirow{8}{*}{$0.142^{\mathrm{NS}}$} \\
\hline 1 & $165.60 \pm 4.86$ & $171.53 \pm 3.25$ & $169.60 \pm 4.54_{\mathrm{A}}$ & $173.13 \pm 3.24$ & $162.53 \pm 3.53$ & $173.67 \pm 4.0$ & \\
\hline 3 & $165.60 \pm 4.77$ & $171.93 \pm 3.26$ & $172.27 \pm 4.59_{\mathrm{A}}$ & $174.13 \pm 2.66$ & $163.40 \pm 3.56$ & $176.40 \pm 4.04_{\mathrm{A}}$ & \\
\hline 6 & $162.13 \pm 4.64$ & $176.87 \pm 3.39_{\mathrm{A}}$ & $174.00 \pm 4.96_{\mathrm{A}}$ & $173.20 \pm 2.61$ & $167.27 \pm 3.58_{\mathrm{A}}$ & $178.90 \pm 3.85_{\mathrm{A}}$ & \\
\hline $12^{\$}$ & $160.27 \pm 4.60_{\mathrm{A}}$ & $179.80 \pm 3.49_{\mathbf{B}}$ & $177.80 \pm 4.94_{\text {в }}$ & $172.00 \pm 2.49$ & $170.00 \pm 3.57 \mathrm{~A}$ & $183.80 \pm 3.72$ в & \\
\hline $24^{\$}$ & $159.27 \pm 4.60_{\mathrm{A}}$ & $181.80 \pm 3.52$ в & $174.93 \pm 4.77_{\text {в }}$ & $171.40 \pm 2.46$ & $170.86 \pm 3.47_{\mathrm{A}}$ & $183.80 \pm 34.89$ в & \\
\hline 36 & $159.29 \pm 4.76_{\mathrm{A}}$ & $181.87 \pm 2.92_{\text {в }}$ & $175.57 \pm 4.71_{\text {в }}$ & $170.93 \pm 2.47$ & $169.93 \pm 3.28_{\mathrm{A}}$ & $178.00 \pm 3.55 \mathrm{~A}$ & \\
\hline 48 & $157.39 \pm 4.93_{\mathrm{A}}$ & $176.08 \pm 3.24_{\mathrm{A}}$ & $170.13 \pm 4.62_{\mathrm{A}}$ & $170.26 \pm 2.49$ & $168.33 \pm 3.40_{\mathrm{A}}$ & $178.73 \pm 3.90_{\mathrm{A}}$ & \\
\hline
\end{tabular}

Within columns, AB indicates significant differences in effects from baseline $(\mathrm{p}<0.0001)$. Significant time-dependent decrease in mean total serum cholesterol concentration in male AML subgroup and increase in both male and female HCZ and AML-HCZ subgroups are presented; AML, Amlodipine 10mg; HCZ, Hydrochlorothiazide 25mg; AML-HCZ, Amlodipine 5-10mg / Hydrochlorothiazide 25mg combination; \$, Combination treatment: Weeks 24-48 (AML), Weeks 12-48 (HCZ); NS, Not Significant; (N = 15 per subgroup)

Table 3. Effects of AML and HCZ Combination Therapy on Triglycerides (mg/dl) in Hypertensive Subjects for 48 weeks

\begin{tabular}{|c|c|c|c|c|c|c|c|}
\hline & \multicolumn{3}{|c|}{ Treatment Subgroups (Male) } & \multicolumn{3}{|c|}{ Treatment Subgroups (Female) } & \multirow[b]{2}{*}{ Gender Effect } \\
\hline Week & AML & HCZ & AML-HCZ & AML & $\mathrm{HCZ}$ & AML-HCZ & \\
\hline 0 & $79.73 \pm 3.33$ & $82.53 \pm 1.79$ & $87.93 \pm 3.30$ & $83.66 \pm 3.18$ & $76.48 \pm 1.25$ & $90.87 \pm 2.05$ & \multirow{8}{*}{$0.946^{\mathrm{NS}}$} \\
\hline 1 & $79.92 \pm 3.55$ & $82.74 \pm 1.78$ & $92.87 \pm 3.16_{\mathrm{A}}$ & $83.47 \pm 3.38$ & $76.60 \pm 1.23$ & $95.60 \pm 2.33_{\mathrm{A}}$ & \\
\hline 3 & $79.20 \pm 3.57$ & $83.07 \pm 1.76$ & $97.47 \pm 3.16_{\mathrm{A}}$ & $84.00 \pm 3.30$ & $77.20 \pm 1.32$ & $99.33 \pm 2.35$ в & \\
\hline 6 & $78.73 \pm 3.47$ & $85.87 \pm 1.72_{\mathrm{A}}$ & $102.20 \pm 3.39_{\mathrm{B}}$ & $83.73 \pm 3.29$ & $79.60 \pm 1.37$ & $102.80 \pm 2.31_{\text {в }}$ & \\
\hline $12^{\$}$ & $78.87 \pm 3.47$ & $83.13 \pm 1.76$ & $106.20 \pm 3.39_{\text {в }}$ & $84.40 \pm 3.11$ & $81.87 \pm 1.53_{\mathrm{A}}$ & Is not $106.73 \pm 2.20_{\mathrm{C}}$ & \\
\hline $24^{\$}$ & $76.67 \pm 3.43$ & $89.00 \pm 1.92_{\text {в }}$ & $104.40 \pm 3.40_{\text {в }}$ & $82.27 \pm 3.17$ & $81.87 \pm 1.40_{\mathrm{A}}$ & $104.27 \pm 2.18_{\mathrm{C}}$ & \\
\hline 36 & $75.93 \pm 3.68_{\mathrm{A}}$ & $89.47 \pm 1.86_{\mathrm{B}}$ & $102.43 \pm 3.08_{\text {в }}$ & $81.73 \pm 2.99$ & $81.13 \pm 1.65_{\mathrm{A}}$ & $100.93 \pm 2.01_{\mathbf{B}}$ & \\
\hline 48 & $74.00 \pm 3.62_{\mathrm{A}}$ & $86.87 \pm 1.89_{\mathrm{A}}$ & $93.73 \pm 3.19_{\mathrm{A}}$ & $81.47 \pm 3.00$ & $80.80 \pm 1.96_{\mathrm{A}}$ & $96.50 \pm 2.02_{\mathrm{A}}$ & \\
\hline
\end{tabular}

Time-dependent significant differences within columns are indicated by $\mathrm{ABC}(\mathrm{p}<0.0001)$. There are significant increases in mean serum triglyceride concentration in all subgroups except in AML subgroups where there is a significant decrease in the M subgroup; other abbreviations are as used in Table 2; ( $\mathrm{N}=15$ per subgroup) 
Table 4. Effects of AML and HCZ Combination Therapy on High Density Lipoprotein Cholesterol (mg/dl) in Hypertensive Subjects for 48 weeks

\begin{tabular}{|c|c|c|c|c|c|c|c|}
\hline & \multicolumn{3}{|c|}{ Treatment Subgroups (Male) } & \multicolumn{3}{c|}{ Treatment Subgroups (Female) } & AML-HCZ \\
\hline Week & AML & HCZ & AML-HCZ & AML & HCZ & AMder Effect \\
\hline 0 & $34.67 \pm 1.77$ & $38.33 \pm 1.55$ & $40.00 \pm 1.36$ & $39.13 \pm 0.66$ & $34.80 \pm 1.92$ & $39.53 \pm 1.30$ & \\
\hline 1 & $34.93 \pm 1.76$ & $38.33 \pm 1.53$ & $40.87 \pm 1.42$ & $39.40 \pm 0.61$ & $34.87 \pm 1.90$ & $39.27 \pm 0.91$ \\
\hline 3 & $36.07 \pm 1.53$ & $38.40 \pm 1.58$ & $39.26 \pm 1.64$ & $39.20 \pm 1.01$ & $34.53 \pm 1.98$ & $36.73 \pm 0.92_{\mathbf{A}}$ \\
\hline 6 & $36.60 \pm 1.56$ & $35.60 \pm 1.44$ & $36.13 \pm 1.63_{\mathbf{A}}$ & $40.13 \pm 0.72$ & $32.46 \pm 2.00$ & $33.93 \pm 0.95_{\mathbf{B}}$ & $0.285^{\text {NS }}$ \\
\hline $12^{\mathbf{\$}}$ & $38.33 \pm 1.32_{\mathbf{A}}$ & $33.80 \pm 1.45_{\mathbf{A}}$ & $33.12 \pm 1.61_{\mathbf{A}}$ & $41.47 \pm 0.76$ & $31.00 \pm 1.94_{\mathbf{A}}$ & $31.07 \pm 0.71_{\mathbf{B}}$ \\
\hline $24^{\mathbf{S}}$ & $39.60 \pm 1.39_{\mathbf{A}}$ & $32.80 \pm 1.39_{\mathbf{A}}$ & $31.87 \pm 1.47_{\mathbf{A}}$ & $42.33 \pm 0.81_{\mathbf{A}}$ & $30.87 \pm 1.92_{\mathbf{A}}$ & $29.20 \pm 0.75_{\mathbf{C}}$ \\
\hline 36 & $40.21 \pm 1.55_{\mathbf{A}}$ & $33.93 \pm 1.42_{\mathbf{A}}$ & $33.86 \pm 1.39_{\mathbf{A}}$ & $42.87 \pm 1.86_{\mathbf{A}}$ & $31.73 \pm 1.89_{\mathbf{A}}$ & $32.00 \pm 0.76_{\mathbf{B}}$ \\
\hline 48 & $40.39 \pm 1.6_{\mathbf{A}}$ & $33.73 \pm 1.39_{\mathbf{A}}$ & $36.87 \pm 1.33_{\mathbf{A}}$ & $42.87 \pm 1.10_{\mathbf{A}}$ & $31.80 \pm 1.83_{\mathbf{A}}$ & $36.21 \pm 0.90_{\mathbf{A}}$ & \\
\hline
\end{tabular}

Significant time-dependent differences within columns are indicated by ABC ( $<<0.0001)$. In both male and female subgroups, mean serum high density lipoprotein concentrations are significantly increased ( $\mathrm{p}<0.0001)$ in AML subgroups and decreased in HCZ and AML-HCZ subgroups ( $\mathrm{p}<0.0001)$; other abbreviations are as used in Table 2; $(\mathrm{N}=15$ per subgroup)

The effects of treatment on serum LDL concentrations in the trial subjects are presented in Table 5. The baseline M mean values of $109.53 \pm 2.60,122.55 \pm 1.84$ and $112.26 \pm 2.16 \mathrm{mg} / \mathrm{dl}$ in AML, HCZ, AML-HCZ subgroups respectively, were significantly decreased in AML subgroup and increased in the others $(\mathrm{p}<0.0001)$. At week 48 the mean $\%$ decrease was $4.6 \%$ in AML subgroup and the $\%$ increases were $5.6 \%$ and $4.5 \%$ in HCZ and AMLHCZ subgroups, respectively. The changes in LDL concentrations in the $\mathrm{F}$ subgroups were similar to the $\mathrm{M}$.

Baseline values of $114.20 \pm 2.05,113.53 \pm 2.23$ and $117.27 \pm 2.42 \mathrm{mg} / \mathrm{dl}$ in AML, HCZ and AML-HCZ subgroups respectively, were, at the end of week 48, significantly decreased by $3.0 \%$ in AML subgroup and increased by $11.7 \%$ in $\mathrm{HCZ}$ and $8.0 \%$ in AML-HCZ subgroups $(\mathrm{p}<0.0001)$. The gender differences in $\mathrm{M}$ and $\mathrm{F}$ mean values were not statistically significant $(p<0.782)$. LDL values were negatively correlated with SBP ( $r=-$ 0.1153, $\mathrm{p}=0.0021)$ and DBP $(\mathrm{r}=-0.1172, \mathrm{p}=0.0017)$

Table 5. Effects of AML and HCZ Combination Therapy on Low Density Lipoprotein Cholesterol (mg/dl) in Hypertensive Subjects for 48 weeks

\begin{tabular}{|c|c|c|c|c|c|c|c|}
\hline & \multicolumn{3}{|c|}{ Treatment Subgroups (Male) } & \multicolumn{3}{|c|}{ Treatment Subgroups (Female) } & \multirow[b]{2}{*}{ Gender Effect } \\
\hline Week & AML & $\mathrm{HCZ}$ & AML-HCZ & AML & $\mathrm{HCZ}$ & AML-HCZ & \\
\hline 0 & $109.53 \pm 2.60$ & $122.55 \pm 1.84$ & $112.26 \pm 2.16$ & $114.20 \pm 2.05$ & $113.53 \pm 2.23$ & $117.27 \pm 2.42$ & \multirow{8}{*}{$0.782^{\mathrm{NS}}$} \\
\hline 1 & $111.13 \pm 2.75_{\mathrm{A}}$ & $123.27 \pm 1.90$ & $116.33 \pm 2.05_{\mathrm{A}}$ & $114.67 \pm 2.19$ & $114.27 \pm 2.37$ & $120.47 \pm 2.46$ & \\
\hline 3 & $111.27 \pm 2.69_{\mathrm{A}}$ & $123.40 \pm 1.85$ & $120.20 \pm 2.11_{\mathbf{B}}$ & $112.65 \pm 2.29$ & $115.13 \pm 2.51$ & $124.45 \pm 2.49_{\mathrm{A}}$ & \\
\hline 6 & $110.33 \pm 2.86_{\mathrm{A}}$ & $128.40 \pm 2.05_{\mathrm{A}}$ & $124.27 \pm 2.06_{\text {B }}$ & $112.60 \pm 2.05$ & $122.47 \pm 4.60_{\mathrm{A}}$ & $128.33 \pm 2.40_{\text {B }}$ & \\
\hline $12^{\$}$ & $109.00 \pm 2.79$ & $131.73 \pm 2.11_{\mathrm{A}}$ & $127.80 \pm 2.12_{\mathrm{C}}$ & $111.47 \pm 2.09$ & $125.93 \pm 4.61_{\mathrm{A}}$ & $131.67 \pm 2.29_{\mathrm{B}}$ & \\
\hline $24^{\$}$ & $107.53 \pm 2.61$ & $134.27 \pm 2.27$ B & $124.67 \pm 2.01_{\text {в }}$ & $110.33 \pm 2.26_{\mathrm{A}}$ & $130.20 \pm 5.49_{\mathrm{B}}$ & $128.00 \pm 2.52_{\mathbf{B}}$ & \\
\hline 36 & $105.86 \pm 2.89_{\text {B }}$ & $134.80 \pm 2.08_{\text {B }}$ & $122.43 \pm 2.05_{\text {B }}$ & $110.13 \pm 2.36_{\mathrm{A}}$ & $129.33 \pm 5.25_{\mathbf{B}}$ & $126.13 \pm 2.44_{\text {B }}$ & \\
\hline 48 & $104.54 \pm 2.95_{\text {B }}$ & $129.47 \pm 2.04_{\mathrm{A}}$ & $117.33 \pm 2.43_{\mathrm{A}}$ & $110.73 \pm 2.19_{\mathrm{A}}$ & $120.80 \pm 2.11_{\mathrm{A}}$ & $126.64 \pm 2.47_{\text {B }}$ & \\
\hline
\end{tabular}

Significant time-dependent differences within columns are indicated by ABC ( $\mathrm{p}<0.0001)$. In both male and female subgroups, mean serum low density lipoprotein cholesterol concentrations are decreased in AML subgroups and increased in HCZ and AML-HCZ subgroups; other abbreviations are as used in Table 2; $(\mathrm{N}=15$ per subgroup)

\section{Discussion}

Hypertensive patients, who are at risk for CV events, often present with an abnormal serum lipid profiles [20], as evident from the low baseline HDL levels of patients in the current study. In contrast to previous approaches that focused solely on pharmacological reduction of elevated $\mathrm{BP}$, the present management of hypertension has focused on the need for an integrated approach to reduce overall CV risk [11,37].

In the present study, initiating combination treatment with AML significantly reduced TC, TG, LDL and increased HDL mean values whereas initiating treatment with HCZ or AML-HCZ combination regimens significantly increased TC and TG as well as decreased HDL values. This surprise finding of the superior clinical benefits of AML may be due to the pleiotropic (ancillary) actions (anti-atherosclerotic, anti-oxidant, antiinflammatory, potentiation of nitric oxide activity) of AML, independent of BP reduction [18,38,39,40]. The physicochemical property of AML (positively charged at physiologic $\mathrm{pH}$ ), leads to strong electrostatic interactions with membrane phospholipid head groups and inhibits the ability of cholesterol to increase membrane width. This atheroprotective effect is not shown by other antihypertensive agents (other CCBs, ACEIs) that lack such physicochemical characteristics. By reducing oxidative modification of LDL and membrane lipids as well as lipid peroxide formation, AML exerts particular anti-oxidant properties that inhibit vascular smooth muscle cell proliferation, endothelial dysfunction and the destructive effects of atherosclerosis. Furthermore, AML is reported to have cerebroprotective effect [41].

Although some studies $[42,43]$ report neutral effects of AML on lipid metabolism, others suggest beneficial effects of AML on lipid parameters as evident in our study. Many studies, which confirm our present data in $\mathrm{HCZ}$ group, have consistently reported that when used for antihypertensive treatment, thiazides including $\mathrm{HCZ}$ increase TC (by 5-7\%), TG, LDL and decrease HDL particularly in patients with diabetes. The rise in TC, which was dose-dependent and greater in blacks, was paralleled by a rise in LDL [22,24,44]. According to Lakshman et al. [44], the deleterious effects of thiazide on lipid profile are mainly observed in the short-term and almost disappear in long-term studies that last for 5 years or more.

As earlier observed, AML is an attractive option in combination therapy because it exhibits an array of 
beneficial additive effects on $\mathrm{CV}$ health. Thiazide-type diuretics are useful tools of considerable therapeutic importance as first-line agents in the treatment of hypertension because they have been proved to reduce $\mathrm{CV}$ morbidity and mortality in systolic and diastolic forms of hypertension and are cheap [25,30]. However, two recent large prospective studies tend to cast doubt on the role of thiazides in combination therapy. Firstly, the BP-lowering arm of the Anglo-Scandinavian Cardiac Outcomes Trial (ASCOT-BPLA) [45], was a large-scale clinical trial in which 19,257 patients, 40 to 79 years of age, were randomly assigned to receive either AML (5-10mg) adding perindopril (4-8mg) as required, or atenolol (50$100 \mathrm{mg})$ adding bendroflumethiazide $(1.25-2.5 \mathrm{mg})$ and $\mathrm{K}^{+}$ as needed. At 5.5 years of follow-up, the trial was prematurely terminated because the AML/ACEI regimen had already demonstrated superiority over atenolol/bendroflumethiazide and $\mathrm{K}^{+}$by preventing more $\mathrm{CV}$ end points, being associated with fewer cases of newonset diabetes and having a more favourable impact on lipids, glucose and potassium blood levels [45].

Secondly, in the Avoiding Cardiovascular Events Through Combination Therapy in Patients Living with Systolic Hypertension (ACCOMPLISH) Trial, 11,506 patients with hypertension who were at high risk for events, received treatment with either benazepril plus AML or benapril plus HCZ. The primary end-point was a composite of death from CV causes, non-fatal myocardial infarction (MI), non-fatal stroke, hospitalization for angina, resuscitation after sudden cardiac arrest and coronary revascularization. The trial was stopped early when data showed a $20 \%$ relative risk reduction favouring benazepril/AML combination despite their causing similar reductions in office and ambulatory BP values [46].

The right conclusion of the ACCOMPLISH study [46] is that $\mathrm{HCZ}$ in a dose of $\leq 25 \mathrm{mg}$ may be less effective in preventing $\mathrm{CV}$ disease than AML in a dose of $10 \mathrm{mg}$. But it has become a provoking debate that this study may have an effect on the development of practice guidelines because the results of a fixed combination of ACEI/AML has demonstrated $\mathrm{CV}$ superiority over a fixed combination of ACEI/HCZ, thus relegating thiazides to third-line therapy. However, since the study population was composed of complicated patients with hypertension and prior history of coronary heart disease (CHD), diabetes or organ damage, it is unclear to what extent these findings can be extrapolated to less uncomplicated hypertensive subjects, such as those in this study. A more recent study [21] also showed that despite similar reductions in BP, valsartan-HCZ combination adversely affected serum lipids as well as LDL subfraction profile unlike valsartanAML combination which exerted beneficial effects.

\section{Conclusion}

In conclusion, it is now evident that hypertension is a formidable adversary which must be addressed with the full repertoire of therapeutic armamentarium particularly through combination therapy. This study has indicated that in this black hypertensive patients with uncomplicated stages 1 and 2 hypertension, maximum benefits on lipid profiles may be derived from a long-term AML and HCZ combination therapy when treatment is initiated with a regimen of $\mathrm{AML}$ to which $\mathrm{HCZ}$ is subsequently added, instead of a regimen of HCZ to which AML is later added or a regimen of $a b$ initio AML-HCZ combination therapy. To our knowledge, this is the first report of the effects of AML and HCZ combination therapy on lipid profiles in hypertensive Nigerians. However, because of the small number of patients studied, caution should be exercised in making deductions from our data or extrapolating our findings to hypertensive black patients in general. Further research in this regard is necessary

\section{Competing Interests}

The authors have no competing interests.

\section{Acknowledgements}

The authors are indebted to the Managements of the hospitals and patients used for this study as well as Neimeth International Pharmaceuticals, Nigeria for donation of amlodipine (Amlovar ${ }^{\mathrm{R}}$ ) tablets and the Nigerian Representative of Novartis Pharma SAS France for donation of hydrochlorothiazide $\left(\right.$ Esidrex $^{\mathrm{R}}$ ) tablets for the study.

\section{References}

[1] Kearney, P.M., Whelton, M., Reynolds, K., Muntner, P., Whelton, P.C. and He, J., "Global burden of hypertension: analysis of worldwide data," Lancet, 365 (9455), 217-223, Jan. 2005.

[2] Gunaranthne, A., Patel, J.V., Potluri, R., Gill, P.S., Hughes E.A. and Lip, G.Y.H., "Secular trends in the cardiovascular risk profile and mortality of stroke admissions in an inner city, multiethnic population in the United Kingdom (1997-2005)," Journal of Human Hypertension, 22 (1), 18-23, Jan. 2008.

[3] Akinkugbe, O.O., "Current epidemiology of hypertension in Nigeria". Archives of Ibadan Medicine, 1, 3-5, 2003.

[4] Imam, I. and Olorunfemi, G., "The profile of stroke in Nigeria's federal capital territory," Tropical Doctor, 32 (4), 209-212, Oct. 2002.

[5] Ike, S.O., "Prevalence of hypertension and its complications among medical admissions at the University of Nigeria Teaching Hospital, Enugu (Study 2)," Nigerian Journal of Medicine, 18 (1), 68-72, Jan. 2009.

[6] Hokanson, J.E. and Austin, M.A., "Plasma triglyceride level is a risk factor for cardiovascular disease independent of high density lipoprotein: a meta-analysis of population based prospective studies," Journal of Cardiovascular Risk, 3 (2), 213-219, Apr. 1996.

[7] Halperin, R.O., Sesso, H.D., Ma, J., Buring, J.E., Stampfer, M.J. and Gaziano, J.M., "Dyslipidemia and the risk of incident hypertension in men," Hypertension, 47 (1), 45-50, Jan. 2006.

[8] NCEP, "Third Report of the National Cholesterol Education Program (NCEP) Expert Panel on Detection, Evaluation and Treatment of High Blood Cholesterol in Adults (Adult Treatment Panel III) final report," Circulation, 106 (25), 3143-3421, 2002.

[9] Sever, P.S., Poulter, N.R. and Elliot, W.J., "Blood pressure reduction is not the only determinant of outcome," Circulation, 113, 2754-2772, 2006.

[10] Collins, R., Armitage, J., Parish, S., Sleight, P., Peto R., Heart Protection Study Collaborative Group, "Effects of cholesterollowering with simvastatin on stroke and other major vascular events in 20536 people with cerebrovascular disease or other highrisk conditions," Lancet, 363 (9411), 757-767, Mar. 2004.

[11] Bronas, U.G. and Leon A.S., "Lifestyle modifications for its prevention and management," American Journal of Lifestyle Medicine, 3 (6), 425-439, Nov. 2009. 
[12] Gradman, A.H. and Acevedo, C., "Evolving strategies for the use of combination therapy in hypertension". Current Hypertension Reports, 4 (5), 343-349, Oct. 2002.

[13] Chobanian, A.V., Bakris, G.L., Black, H.R., Cushman, W.C., Green, L.A., et al., "The seventh report of the joint national committee on prevention, detection, evaluation and treatment of high blood pressure: The JNC 7 report," The Journal of the American Medical Association, 289 (19), 2560-2572, May 2003.

[14] Williams, B., Poulter, N.R., Brown, M.J., Davis, M., Mclnnes, G.T., et al., "British hypertension society guidelines for hypertension management 2004 (BHS-IV): Summary," British Medical Journal, 328 (7440), 634-640, Mar. 2004.

[15] Mancia, G., de Backer, G., Dominiczak, A., Cifkova, R., Fagard, R., Germano, G., et al., "Guidelines for the management of arterial hypertension: The task force for the management of arterial hypertension of the European Society of Hypertension (ESH) and of the European Society of Cardiology (ESC)," Journal of Hypertension, 25 (6), 1105-1187, Jun. 2007.

[16] Mancia, G., Laurent, S., Agabiti-Rosei, E., Ambrosioni, E., Burnier, M., et al., "Reappraisal of European guidelines on hypertension management: A European society of hypertension task force document," Journal of Hypertension, 27 (11), 21212158, Nov. 2009

[17] Wong, M.C.S., Jiang, J.Y., Ali, M.K., Fung, H., Griffiths, S., and Mercer, S.W., "Antihypertensive drug class and dyslipidemia: risk association among chinese patients with uncomplicated hypertension," Journal of Human Hypertension, 22 (9), 648-651, Sep. 2008.

[18] Koh, K.K., Quon, M.J., Han, S.H., Lee, Y., Kim, S.J., Koh, Y. and Shin, E.K., "Distinct vascular and metabolic effects of different classes of antihypertensive drugs," International Journal of Cardiology, 140 (1), 73-81, Apr. 2010.

[19] Leonetti, G., "Effects of nilvadipine and amlodipine in patients with mild to moderate essential hypertension: A double blind, prospective, randomized clinical trial," Current Medical Research and Opinion, 21 (6), 951-958, Jun. 2005.

[20] Nandeesha, H., Pavithran, P. and Madanmohan, T., "Effect of antihypertensive therapy on serum lipids in newly diagnosed essential hypertensive men," Angiology, 60 (2), 217-220, Apr. 2009

[21] Christogiannis, L.G., Kostapanos, M.S., Tellis, C.C., Millionis, H.J., Tselepis, A.D. and Elisaf, M.S., "Distinct effects of fixed combinations of valsartan with either amlodipine or hydrochlorothiazide on lipoprotein subfraction profile in patients with hypertension," Journal of Human Hypertension, 27 (1), 4450, Jan. 2013.

[22] Tejada, T., Fornoni, A., Lenz, O. and Materson, B.J., "Combination therapy with renin-angiotensin system blockers: Will amlodipine replace hydrochlorothiazide?" Current Hypertension Reports, 9 (4), 284-290, Aug. 2007.

[23] Messerli, F.H., Bangalore, S. and Julius, S., "Risk/benefit assessment of $\beta$-blockers and diuretics precludes their use for firstline therapy in hypertension," Circulation, 117 (20), 2706-2715, May 2008.

[24] Ellison, D.H. and Loffing, J., "Thiazide effects and adverse effects: Insights from molecular genetics," Hypertension, 54 (2), 196-202, Aug. 2009.

[25] Grossman, E., Verdecchia, P., Shamiss, A., Angeli F., and Reboldi, G., "Diuretic treatment of hypertension," Diabetes Care, 34 (Suppl 2), S313-S319, May 2011.

[26] Ma, L., Wang, W., Zhao, Y., Zhang, Y., Deng, Q., et al., "Combination of amlodipine plus angiotensin receptor blocker or diuretics in high-risk hypertensive patients: A 96-week efficacy and safety study," American Journal of Cardiovascular Drugs, 12 (2), 137-142, Apr. 2012.

[27] Sareli, P., Radevski, I.V., Valtchanova, Z.P., Libhaber, E., Candy, G.P., et al., "Efficacy of different drug classes used to initiate antihypertensive treatment in black subjects: Results of a randomized trial in Johannesburg, South Africa," Archives of Internal Medicine, 161 (7), 965-971, Apr. 2001.

[28] Brewster, L.M., van Montfrans, G.A. and Kleijnen, J., "Systematic review: Antihypertensive drug therapy in black patients," Annals of Internal Medicine, 141 (8), 614-627, Oct. 2004.

[29] Isah, A.O., Obasohan, A.O. and Okpako, L.O., "Open evaluation of amlodipine in the monotherapeutic treatment of mild to moderate hypertension in Nigerian patients," Current Therapeutic Research, 52, 812-818, 1992.
[30] Wright, J.T., Dunn, J.K., Cutler, J.A., Davis, B.R., Cushman, W.C., et al., "Outcomes in hypertensive black and nonblack patients treated with chlorthalidone, amlodipine and lisinopril," The Journal of the American Medical Association, 293 (13), 15951608, Apr. 2005.

[31] Salako, B.L., Kadiri, S., Walker, O. and Fehintola, F.A., "Evaluation of lacidipine (a calcium blocker) in the treatment of hypertension in black African people: A double-blind comparison with hydrochlorothiazide," African Journal of Medicine and Medical Science, 27 (1-2), 73-75, Mar. 1998.

[32] Iyalomhe, G.B.S., Omobgai, E.K.I. and Ozolua, R.I., "Antihypertensive and some biochemical effects of hydrochlorothiazide and furosemide in some Nigerians," Journal of Medical Sciences, 7 (6), 977-983, Aug. 2007.

[33] Pickering, T.G., Hall, J.E., Appel, L.J., Falkner, B.E., Graves, J., et al., "Recommendations for blood pressure measurement in humans and experimental animals Part 1: blood pressure measurement in humans: A statement for professionals from the Subcommittee of Professional and Public Education of the American Heart Association Council on High Blood Pressure Research," Hypertension, 45 (1), 142-161, Jan. 2005.

[34] Pesce, A.J. and L.A. Kaplan, 1987. Methods in Clinical Chemistry. Mosby Company, St. Louis, USA, ISBN-13: 9780801638299, Pages: 1366.

[35] Friedewald, W.T., Levy, R.I. and Fredrickson, D.S., "Estimation of the concentration of low-density lipoprotein cholesterol in plasma, without use of the preparative ultra-centrafuge," Clinical Chemistry, 18 (6), 499-502, Jun. 1972.

[36] Statistical Analysis System, "The SAS for Windows," Release 8.20, SAS Institute, Carry, NC., USA, 2004.

[37] Iyalomhe, G.B.S. and Iyalomhe, S.I., "Hypertension-related knowledge, attitudes and life-style practices among hypertensive patients in a sub-urban Nigerian community," Journal of Public Health amd Epidemiology, 2 (4), 71-77, Jul. 2010.

[38] Mason, R.P., Marche, P. and Hintze, T.H., "Novel vascular biology of third-generation L-type calcium channel antagonists: Ancillary actions of amlodipine," Arteriosclerosis, Thrombosis and Vascular Biology, 23 (12), 2155-2163, Dec. 2003.

[39] Toba, H., Nakagawa, Y., Miki, S., Shimizu, T., Yoshimura, A., et al., "Calcium channel blockades exhibit anti-inflammatory and antioxidative effects by augumentation of endothelial nitric oxide synthase and the inhibition of angiotensin converting enzyme in the $\mathrm{N}(\mathrm{G})$-nitro-L-arginine methylester-induced hypertensive rat aorta: vasoprotective effects beyond the blood pressure- lowering effects of amlodipine and manidipine," Hypertension Research, 28, 689-700, 2005.

[40] Mayer, B., "Translocation of endothelial nitric oxide synthase: Another feat of amlodipine, a cardiovascular jack-of-all-trades," Cardiovascular Research, 71 (3), 411-413, Aug. 2006.

[41] Fournier, A., Messerli, F.H., Achard, J.M. and Fernandez, L., "Cerebroprotection mediated by angiotensin II: A hypothesis supported by recent randomized clinical trials," Journal of the American College of Cardiology, 43 (8), 1343-1347, Apr. 2004.

[42] Brook, R.D., "Mechanism of differential effects of antihypertensive agents on serum lipids," Current Hypertension Reports, 2 (4), 370-377, Aug. 2000.

[43] Hernandez, R.H., Armas-Hernandez, M.J., Velasco, M., Israili, Z.H. and Armas-Padilla, M.C., "Calcium antagonists and atherosclerosis protection in hypertension," American Journal of Therapeutics, 10 (6), 409-414, Nov. 2003

[44] Lakshman, M.R., Reda, D.J., Materson, B.J., Cushman, W.C. and Freis, E.D., "Diuretics and $\beta$-blockers do not have adverse effects at 1 year on plasma lipid and lipoprotein profiles in men with hypertension," Archives of Internal Medicine, 159, 551-558, 1999.

[45] Dahlof, B., Sever, P.S., Poulter, N.R., Wedel, H., Beevers, D.G., et al., "Prevention of cardiovascular events with an antihypertensive regimen of amlodipine adding perindopril as required versus atenolol adding bendroflumethiazide as required, in the Anglo-Scandinavian Cardiac Outcomes Trial-Blood Pressure Lowering Arm (ASCOT-BPLA): a multicentre randomized controlled trial," Lancet, 366 (9489), 895-906, Sep. 2005.

[46] Jamerson, K., Weber, M.A., Bakris, G.L., Dahlof, B., Pitt, B., et al., "Benazepril plus amlodipine or hydrochlorothiazide for hypertension in high-risk patients," The New England Journal of Medicine, 359 (23), 2417-2428, Dec. 2008. 